\title{
The importance of security for people and collections in libraries
}

\author{
Andra Manuela Botez \\ $\mathrm{PhDc}$, Transilvania University of Brasov \\ E-mail andra.manu@ymail.com \\ Angela Repanovici \\ Professor, PhD, Transilvania University of Brasov \\ E-mail arepanovici@unitbv.ro
}

The security of collections and people in a library embraces a large number of responsibilities. The costs of maintaining, processing, and acquiring collections are high. If they are stolen or damaged, it can be difficult, if not impossible, to replace. Also, in recent years, personal security is a problem due to numerous terrorist attacks. This article highlights the importance of security in libraries and the view of librarians about the implementation of a security system based on facial recognition in the library in which they operate.

Keywords: library security; collections security; personal security; library access; facial recognition

\section{Introduction}

The fact that security has become a key topic of criminological analysis, of particular importance, reflects the uncertainty of twenty-first century society (Zedner 2014).

In an attempt to understand the concept of security, Brooks (2009) mentions that exposure to terrorist attacks in many parts of the world (London, 2005; Jakarta, 2004; Spain, 2004; Bali, 2002 and New York, 2001) has raised social concern over the ability of governments to protect its citizens. According to Zedner (2014), new crime prevention techniques and community safety initiatives combine to create a security concern among local authorities, partnerships between agencies, voluntary groups, as well as private citizens.

A number of studies have approached the issue of collections security, as well as the personal security of visitors and library staff. Also, various studies have described how security breaches and incidents can affect the provision of library services to users (Maidabino \& Zainab 2012). Thus, Latuszek (2002) mentions that although many libraries are still in predominantly quiet locations in terms of noise and crime, it is not difficult to notice a pattern of unease steadily increasing at public and academic libraries.

Zedner (2014) believes that security is a promiscuous concept, being implemented in many areas (social security, financial security, environmental security, health and safety, human security, international relations and peacekeeping, etc.). Thus, security is the state of "being protected against threats" - either by neutralizing them, by avoiding, or by not risking.

Maidabino and Zainab (2012) mention in their study that the purpose of libraries is to provide access to information resources in both print and non-print formats. They believe that balancing access and security in libraries is difficult but at the same time a necessary task. Even if the library focuses on popular reading materials, or reference books, the cost of replacing these materials, when they have been stolen or damaged can become prohibitive. So, libraries should be able to use

Revista Română de Biblioteconomie şi Ştiința Informării = Romanian Journal of Library and Information Science ISSN 1841-1940 • Volume 13 Issue 12017 pp. 11-20

This work is licensed under a Creative Commons Attribution-NonCommercial-NoDerivatives 4.0 International License 
the resources they have, not to replace items, but to build new and used collections. (Kahn 2007) Some libraries have attempted to reduce the amount of damage and destruction (especially breakage of pages) done to their print materials by reducing photocopying costs and by offering the possibility to print two pages at the same time. Others have extended their borrowing periods to four weeks, with additional renewal periods, allowing people to have the materials in their possession until they finished reading a book or watching a movie. Renewal from home, online or by phone also makes it easier for patrons to bring their books back and renew them. However, there are still those patrons who pull the books out of the covers or who don't bother to return them (Kahn 2007).

Latuszek (2002) made a review of articles describing incidents due to library visitors to highlight the importance of security plans. Through this article, the author wishes to outline increased security awareness in libraries, highlighting technological questions and policy concerns.

Maidabino and Zainab (2012) proposed a tool to evaluate the implementation of collections security in university libraries. This tool encompasses five factors: managing collections security, operations and processes, people's issues, physical and technical aspects of collections security, and security culture in libraries.

Harris and DiMarco (2010) present a perspective on how Mansfield University, Pennsylvania, addressed the issue of personal security, specifically in the library. The purpose of this article is to help libraries in planning for the worst scenarios, covered issues including self-locking, planning, policies and procedures, physical security, visitor issues, secure places in the library, etc.

Westenkirchner (2008) offers in his article instructions for libraries wishing to acquire an integrated digital video surveillance system based on the experience of the Auburn University Library. The article covers the technical aspects of closed circuit television (CCTV) and Internet Protocol (IP) integrated video surveillance systems, providing a brief explanation of how the equipment works.

\section{Methodology}

To improve the security of individuals, as well as collections in a library, we are proposing the implementation of a system for facial recognition of users. There are security systems for collections, but in the context of terrorism, we are interested in having people of good faith who have access inside the library

Face recognition is a technology that uses the computer to analyze face images and extract features for recognizing the subject's identity (Yang et al 2002). According to the literature, the facial recognition process comprises the following steps (Data Protection Working Party 2012):

a) Image acquisition: the process of capturing an image representing a person's face;

b) Face detection: the process of detecting the presence of faces in the image and marking the area where they appear;

c) Extraction of features: the process of isolating and transferring the repeatable and distinctive features of a person's digital image;

d) Comparison: the process of measuring the similarity between a set of characteristics (the sample) and another series already entered in the system. The main objectives of the comparison are identification and authentication /verification;

e) Finding the pair elements: determine whether the scores obtained in step four are large enough to declare a match between the generated and the recorded template. Rules governing the level at which a match between the two templates can be declared are often configurable by the end-user 
so that it can determine the level of security that the system needs to function according to utility. (Woodward et al 2003).

The statistical research aimed to determine the views of librarians, both with executive and management functions, on security systems in libraries, as well as on the implementation of a system for facial recognition of users.

The following assumptions of research have been formulated:

1. Librarians concerned with the security of individuals, in the context of terrorism, are eager to implement a facial recognition system in the library in which they operate.

2. Librarians who believe that the most appropriate biometric recognition system for security of collections and individuals is facial recognition, would agree to implement such a system in the library in which they operate.

3. Librarians who have confidence in facial recognition systems agree to implement such a system in the library in which they operate.

4. Librarians who work in large libraries agree to implement a facial recognition system.

5. The higher the level of education of librarians, the more they are willing to implement a facial recognition system in their library.

6. Librarians with a leading position are more likely to implement a facial recognition system in their library.

7. Librarians with work experience of more than 31 years are more likely to implement a facial recognition system in the library in which they work.

The working methodology used, relevant for identifying respondents' views on the security of collections and individuals, was the application of an online questionnaire, consisting of 16 questions. Respondents were notified before filling in the questionnaires on the confidentiality regime of the collected data. The questionnaire was designed on the basis of the concept's operationalization, starting from the definition of security in the library.

The survey comprised 177 respondents, both in Romania and abroad, and was conducted in February / March 2017. Data processing was performed using the SPSS (Statistical Package for Social Sciences) and the Excel program. The questionnaires have been distributed in as many countries as possible for better representativeness. Among these are: Romania, Moldova, Albania, Armenia, Belarus, Bosnia and Herzegovina, Bulgaria, Greece, Ireland, Montenegro, Norway, United Kingdom, Russia, Serbia, Turkey, Hungary. Most respondents are from Romania and Moldova. Out of a total of 177, 93 respondents are from Romania and 50 from Moldova.

The results of this study will be used in the design and implementation of the facial recognition system to be used for users entering libraries.

\section{Results}

For data analysis we used the SPSS program, command Analyze-Descriptive StatisticsFrequencies, which shows how often a response occurs within a variable, and the graphs were created in Excel to be able to view the data more easily.

From a total of 145 librarians in Romania and Moldova, 61.4\% would agree with the implementation of a facial recognition system in the library in which they operate, $12.4 \%$ disagree, and a percentage of $23.4 \%$ did not express their opinion on this approach (Fig. 1).

As for the respondents from abroad, out of a total of 32, 13 agreed to the implementation of a facial recognition system, 11 disagreed and 8 did not express their opinion (Table 1). 
Would you agree with the implementation of a facial recognition system in the library you work?

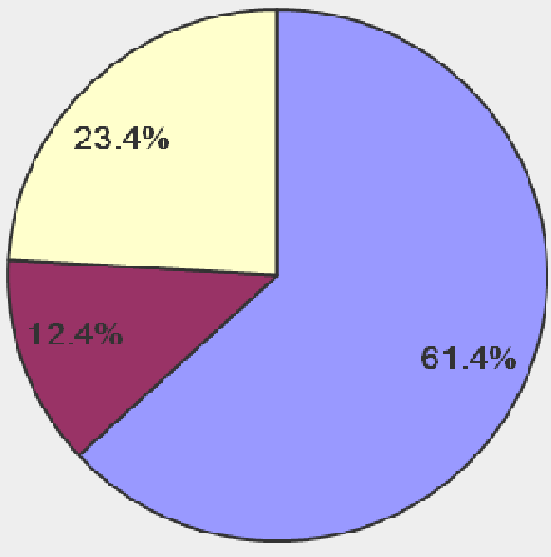

口Yes

a No

미 do not know / No answer

Figure 1. The agreement of librarians in Romania and Moldova to implement a facial recognition system

\begin{tabular}{|c|c|c|c|c|c|}
\hline \multicolumn{2}{|c|}{} & Frequency & Percent & $\begin{array}{c}\text { Valid } \\
\text { Percent }\end{array}$ & $\begin{array}{c}\text { Cumulativ } \\
\text { e Percent }\end{array}$ \\
\hline \multirow{7}{*}{ Valid } & Yes & 13 & 40.6 & 40.6 & 40.6 \\
\cline { 2 - 6 } & No & 11 & 34.4 & 34.4 & 75.0 \\
\cline { 2 - 6 } & $\begin{array}{c}\text { I do not } \\
\text { know / No } \\
\text { answer }\end{array}$ & 8 & 25.0 & 25.0 & 100.0 \\
\cline { 2 - 6 } & Total & 32 & 100.0 & 100.0 & \\
\hline
\end{tabular}

Table 1. The agreement of librarians abroad to implement a facial recognition system

Would you agree with the implementation of a facial recognition system in the library you work?
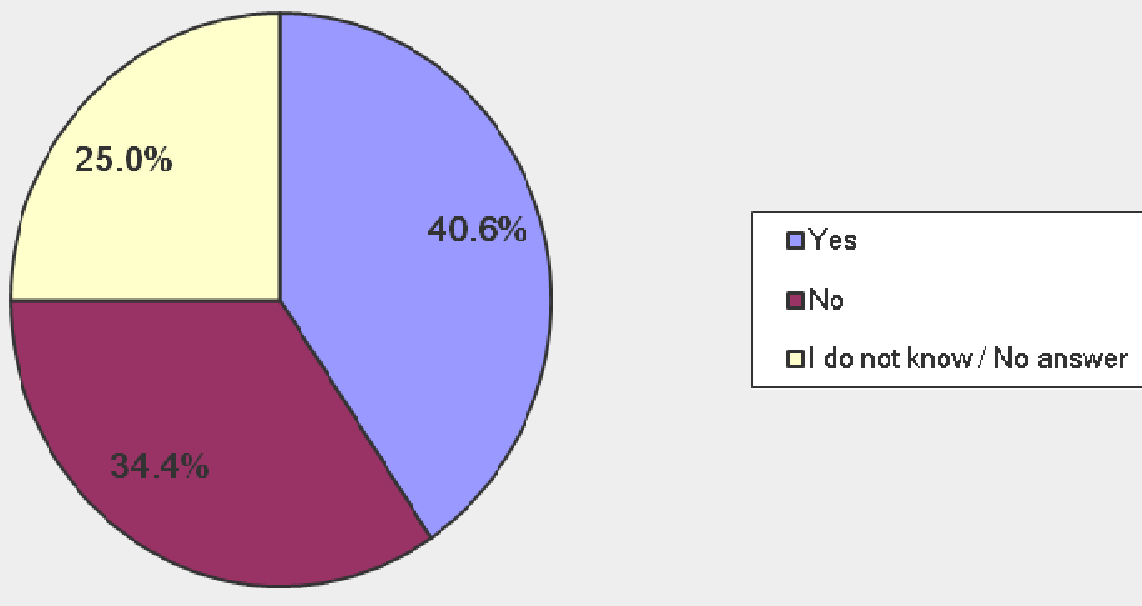

Figure 2. The agreement of librarians abroad to implement a facial recognition system 
It has been proven that librarians in Romania and Moldova have confidence in facial recognition systems. Thus, $38.6 \%$ are fairly confident, $9 \%$ have a lot of confidence and $18.6 \%$ neither much nor a little (Fig.3).

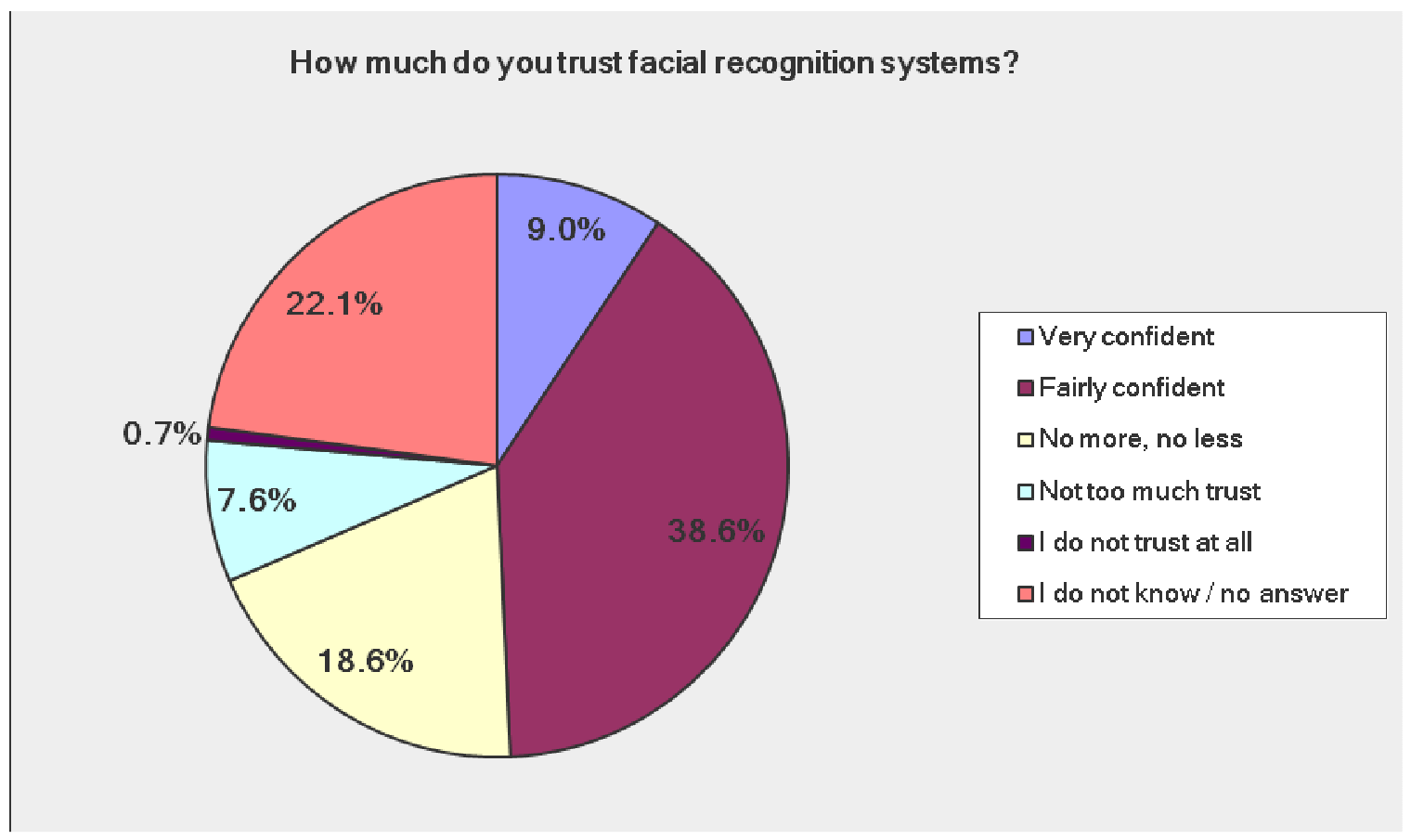

Figure 3. Confidence of respondents in Romania and Moldova on facial recognition systems

When it comes to choosing the safest security system, librarians have chosen biometric recognition systems in a proportion of $62 \%$, in the detriment of RFID (Radio-Frequency Identification) system (Fig.4).

What is, according to your opinion, the safest security system that can be used in libraries?

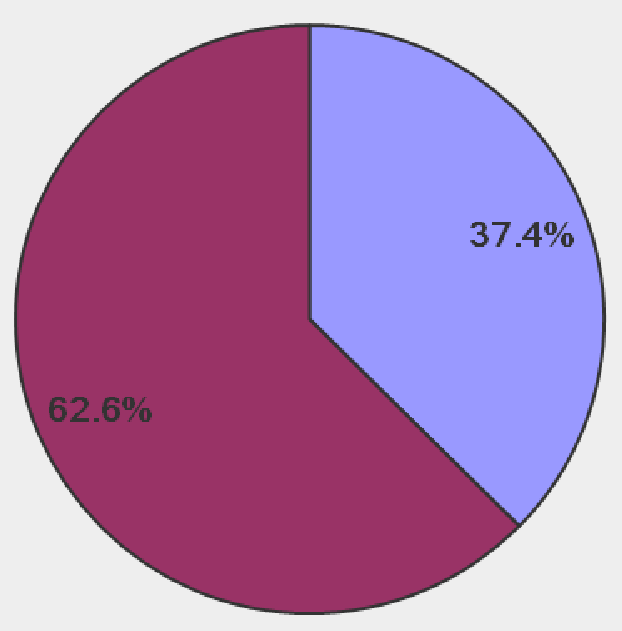

口The RFID

Biometric recognition systems

Figure 4. The safest security system, in the opinion of the respondents in Romania and Moldova 


\section{Statistical hypothesis testing}

Hypothesis 1. Librarians concerned with the security of individuals, in the context of terrorism, are eager to implement a facial recognition system in the library in which they operate.

Next, we will formulate two hypotheses, the null hypothesis (H0) referring to the worst case and the alternative hypothesis (H1), the opposite of the null.

H0 - there is no correlation between the librarians' desire to take action on the security of individuals and the agreement of librarians to implement a facial recognition system;

H1 - there is a correlation between librarians' desire to take action on people's security and the agreement of librarians to implement a facial recognition system;

The probability of guaranteeing the results is $95 \%$, the $5 \%$ error margin is the probability of error and under these conditions, the probability of testing the null hypothesis (p) will be 0.05 .

The general rule of test for a $95 \%$ probability of guaranteeing results: $x_{\text {calculated }}<x_{\text {critic }}=>$ rejects the hypothesis of null H0. Where: $x_{\text {calculated }}=p_{\text {calculated }}$ (Sig.) and $x_{\text {critic }}=p$, and $p=0.05$.

According to the Pearson index, the variable measuring librarians' willingness to take action on the security of individuals in the context of terrorism is correlated to the level of 0.203 , with the variable expressing the agreement of librarians to implement a facial recognition system. Sig $=$ 0.008 is less than $p=0.05$, hence it results that the null hypothesis is rejected and there is correlation between the librarians' desire to take action on the security of individuals and the agreement of librarians to implement a facial recognition system. Sig $=0.008, p<0.01$ indicating a strong link between the two variables. Thus, the more librarians are concerned with the security of individuals in the context of terrorism, the more they are willing to implement a facial recognition system, and vice versa.

The hypothesis that librarians concerned with the security of individuals in the context of terrorism are eager to implement a facial recognition system in the library in which they work is confirmed.

Hypothesis 2. Librarians who believe that the most appropriate biometric recognition system for security of collections and individuals is facial recognition would agree to implement such a system in the library in which they operate.

Next, we will formulate two hypotheses, the null hypothesis (H0) referring to the worst case and the alternative hypothesis (H1), the opposite of the null.

H0 - There is no correlation between librarians' opinion on the most appropriate biometric recognition system for the security of collections and individuals in a library and the agreement of librarians to implement a facial recognition system;

H1 - there is a correlation between librarians' opinion on the most appropriate biometric recognition system for the security of collections and individuals in a library, and the agreement of librarians to implement a facial recognition system;

The general rule of test for a $95 \%$ probability of guaranteeing results: $x_{\text {calculated }}<x_{\text {critic }}=>$ rejects the hypothesis of null H0. Where: $x_{\text {calculated }}=p_{\text {calculated }}$ (Sig.) and $x_{\text {critic }}=p$, iar $p=0.05$.

According to the Pearson index, the variable that describes librarians' opinion of the most appropriate biometric recognition system for the security of collections and people in a library is correlated to 0.335 , with the variable expressing the agreement of librarians to implement a facial recognition system.

$\mathrm{Sig}=0$ is less than $\mathrm{p}=0.05$ hence it results that the null hypothesis is rejected and there is correlation between librarians' opinion about the most appropriate biometric recognition system for the security of collections and individuals in a library and the agreement of librarians to implement a 
facial recognition system. Sig $=0, p<0.01$ indicating a strong link between the two variables. Thus, the more librarians think the most appropriate biometric recognition system for the security of collections and individuals is facial recognition, the more they are willing to implement a facial recognition system, and vice versa.

The hypothesis that librarians who believe that the most appropriate biometric recognition system for the security of collections and individuals is facial recognition would agree with the implementation of such a system in the library in which it operates is confirmed.

\section{Hypothesis 3. Librarians who have confidence in facial recognition systems agree to implement such a system in the library in which they operate.}

Formulation of the null hypothesis $(\mathrm{H} 0)$ and the alternative one $(\mathrm{H} 1)$ :

$\mathrm{HO}$ - there is no correlation between librarians' confidence in facial recognition systems and the agreement of librarians to implement a facial recognition system;

$\mathrm{H} 1$ - there is a correlation between librarians' confidence in facial recognition systems and the agreement of librarians to implement a facial recognition system;

The general rule of test for a $95 \%$ probability of guaranteeing results: $x_{\text {calculated }}<x_{\text {critic }}=>$ rejects the hypothesis of null H0. Where: $x_{\text {calculated }}=p_{\text {calculated }}$ (Sig.) and $x_{\text {critic }}=p$, iar $p=0.05$.

According to the Pearson index, the variable that measures the confidence of librarians in facial recognition systems is correlated to the 0.352 level, with the variable expressing the agreement of librarians to implement a facial recognition system.

$\operatorname{Sig}=0$ is less than $\mathrm{p}=0.05$, resulting in the rejection of the H0 null hypothesis, according to which there is no correlation between librarians' confidence in facial recognition systems and the agreement of librarians to implement a facial recognition system. Sig $=0, p<0.01$ indicating a strong link between the two variables. Thus, the more librarians have confidence in facial recognition systems, the more they are willing to implement a facial recognition system, and vice versa.

The hypothesis that librarians who trust the facial recognition systems agree with the implementation of such a system in the activating library is confirmed.

Hypothesis 4. Librarians who work in large libraries agree to implement a facial recognition system.

Next, we will formulate the two hypotheses (null, alternative):

$\mathrm{HO}$ - there is no correlation between the size of the library in which they work and the agreement of librarians to implement a facial recognition system;

H1 - there is a correlation between the size of the library in which they work and the agreement of librarians to implement a facial recognition system;

The general rule of test for a $95 \%$ probability of guaranteeing results: $x_{\text {calculated }}<x_{\text {critic }}=>$ rejects the hypothesis of null H0. Where: $x_{\text {calculated }}=p_{\text {calculated }}$ (Sig.) and $x_{\text {critic }}=p$, iar $p=0.05$.

In the presented situation, the Pearson coefficient is -0.074 , which is a very poor correlation between the size of the library in which it works and the agreement of librarians to implement a facial recognition system. Sig $=0.337$ is higher than $p=0.05$ where it follows that the assumption of null $\mathrm{H} 0$ is accepted, according to which there is no correlation between the size of the library in which it works and the agreement of the librarians to implement a facial recognition system. 
The hypothesis that librarians working in large libraries agree to implement a facial recognition system is rejected because there is no significant statistical association between the two variables.

Hypothesis 5. The higher the level of education of librarians, the more they are willing to implement a facial recognition system in their library.

Next, we will formulate the two hypotheses (null, alternative):

H0 - there is no correlation between the level of librarians' education and their agreement to implement a facial recognition system;

H1 - there is a correlation between the level of librarians' education and the agreement of librarians to implement a facial recognition system;

The general rule of test for a $95 \%$ probability of guaranteeing results: $x_{\text {calculated }}<x_{\text {critic }}=>$ rejects the hypothesis of null H0. Where: $x_{\text {calculated }}=p_{\text {calculated }}$ (Sig.) and $x_{\text {critic }}=p$, iar $p=0.05$.

The Pearson coefficient is $-0,071$, which is a very poor correlation between librarians 'level of education and their agreement to implement a facial recognition system.

Sig $=0.353$ is higher than $\mathrm{p}=0.05$ where it follows that the assumption of null $\mathrm{H} 0$ is accepted, according to which there is no correlation between the level of librarians' education and their agreement to implement a facial recognition system.

The hypothesis according to which the higher the level of librarians' education, the more they are willing to implement a facial recognition system in the library in which they work is rejected, because there is no significant statistical association between the two variables.

Hypothesis 6. Librarians with a leading position are more likely to implement a facial recognition system in their library.

Formulation of the null hypothesis (H0) and the alternative one (H1):

$\mathrm{HO}$ - there is no correlation between the function of librarians and their agreement to implement a facial recognition system;

$\mathrm{H} 1$ - there is a correlation between the function of librarians and their agreement to implement a facial recognition system;

The general rule of test for a $95 \%$ probability of guaranteeing results: $x_{\text {calculated }}<x_{\text {critic }}=>$ rejects the hypothesis of null H0. Where: $x_{\text {calculated }}=p_{\text {calculated }}$ (Sig.) and $x_{\text {critic }}=p$, iar $p=0.05$.

The Pearson coefficient is $-0,011$, which is a very poor correlation between librarians' function and their agreement to implement a facial recognition system. Sig $=0.884$ is higher than $p=0.05$, therefore it follows that the hypothesis of null $\mathrm{HO}$ is accepted, according to which there is no correlation between the function of librarians and their agreement to implement a facial recognition system.

The hypothesis that librarians with a leading function are more willing to implement a facial recognition system in the library in which they work is rejected because there is no significant statistical association between the two variables. 
Hypothesis 7. Librarians with work experience of more than 31 years are more likely to implement a facial recognition system in the library in which they work.

Formulation of the null hypothesis (H0) and the alternative one (H1):

$\mathrm{H} 0$ - there is no correlation between workplace experience and librarians' agreement to implement a facial recognition system;

H1 - there is a correlation between workplace experience and librarians' agreement to implement a facial recognition system;

The general rule of test for a $95 \%$ probability of guaranteeing results: $x_{\text {calculated }}<x_{\text {critic }}=>$ rejects the hypothesis of null H0. Where: $x_{\text {calculated }}=p_{\text {calculated }}$ (Sig.) and $x_{\text {critic }}=p$, iar $p=0.05$.

The Pearson coefficient is $-0,032$, which is a very poor correlation between workplace experience and librarians' agreement to implement a facial recognition system.

Sig $=0.676$ is higher than $\mathrm{p}=0.05$, resulting that the hypothesis of null $\mathrm{H} 0$ is accepted, according to which there is no correlation between workplace experience and librarians' agreement to implement a facial recognition system.

The hypothesis that librarians with work experience of more than 31 years are more likely to implement a facial recognition system in the library in which they work is rejected because there is no significant statistical association between the two variables.

\section{Conclusions}

As a result of our research, we can specify that most librarians would agree to implement a facial recognition system in the library in which they work to increase security. It was noticed that respondents from abroad were more aware of this approach, compared to those in Romania and Moldova.

Librarians concerned with personal security, in the context of terrorism, are eager to implement a facial recognition system in their library. Also, librarians who believe that the most appropriate biometric recognition system for collections and the security of people is facial recognition, would agree with the implementation of such a system. The degree of trust in facial recognition systems plays an important role in the decision of librarians to increase the security of the library by installing the new system. From the data analyzed, the size of the library, the librarian's function, or the experience of over 31 years in the workplace does not interfere with the decision of librarians to implement the new facial recognition system. Also, the librarian's level of training does not interfere with this decision, perhaps because most have more than average education.

\section{References}

Brooks, D.J (2009) What is security: Definition through knowledge categorization, Security Journal, 23(3), pp.225-239.

Data Protection Working Party (2012) Opinion 02/2012 on facial recognition in online and mobile services, 00727/12/EN WP 192 [online], available: http://ec.europa.eu/justice/data-protection/ article-29/documentation/opinion-recommendation/files/2012/wp192_en.pdf_[accessed 5 March 2017].

Harris, J.L. \& DiMarco, S.R. (2010) Locking Down a University Library: How to Keep People

Safe in a Crisis: A Mansfield University of Pennsylvania Perspective, Library \& Archival Security, 23(1), pp.27-36.

Kahn, MB. (2007) Library Security and Safety Guide to Prevention, Planning, and Response, 
University of Bergen Library [online], available: https:/ebookcentral-proquest-com.pva.uib.no/lib/ bergen-ebooks/reader.action?docID=474203\&ppg=1 [accessed 5 March 2017].

Latuszek Jr., T. (2002) Library Security: A Growing Awareness, Library \& Archival Security, 15 (2), pp.3-7.

Maidabino, A.A. \& Zainab, A.N. (2012) A holistic approach to collection security implementation in university libraries, Library Collections, Acquisition and Technical Services, 36(3-4), pp.107120 .

Westenkirchner, S. (2008) Integrated Library Security Systems, Library \& Archival Security, 21 (2), p.159.

Woodward, J.D., Horn, C., Gatune, J. and Thomas A. (2003) Biometrics.A Look at Facial Recognition, Prepared for the Virginia State Crime Commission, Santa Monica, CA: RAND Public Safety and Justice, ISBN: 0-8330-3302-6.

Yang, M.H., Kriegman, D.J. and Ahuja N. (2002) Detecting faces in images: a survey, IEEE Transactions on Pattern Analysis and Machine Intelligence, 24 (1), pp. 34-58.

Zedner, L. (2014) Security, University of Bergen Library [online], available https://ebookcentralproquest-com.pva.uib.no/lib/bergen-ebooks/detail.action?docID=425617 [accessed $5 \mathrm{March}$ 2017]. 